\title{
Conformational Space of the Pseudosaccharin Allyl Ether 3-(Allyloxy)-1,2-benzisothiazole 1,1-Dioxide in Gas Phase and in Rare Gas Matrices
}

\author{
Andrea Gómez-Zavaglia,,,$+ \neq$ Agnieszka Kaczor,,$\pitchfork$ Rui Almeida,,$+\|$ \\ Maria de Lurdes S. Cristiano," and Rui Fausto*, \\ Department of Chemistry, University of Coimbra, Coimbra, P-3004-535, Portugal, Faculty of Pharmacy and \\ Biochemistry, University of Buenos Aires, C.P. 1113 Buenos Aires, Argentina, Faculty of Chemistry, \\ Jagiellonian University, Ingardena 3, 30-060 Krakow, Poland, and Department of Chemistry and Biochemistry, \\ F.C.T., and CCMAR, University of Algarve, Campus de Gambelas, 8005-039 Faro, Portugal
}

Received: September 4, 2007; In Final Form: November 20, 2007

\begin{abstract}
In this work, the conformational space of the pseudosaccharyl ether 3-(allyloxy)-1,2-benzisothiazole 1,1dioxide (ABID) has been studied by means of infrared spectroscopy and density functional theory (DFT) calculations. Five different low energy conformers (TSk, TC, GSk, GS $k^{\prime}$ and $G C$, with relative energies of $0.00,1.97,2.00,3.82$ and $6.02 \mathrm{~kJ} \mathrm{~mol}^{-1}$, respectively) were found on the DFT(B3LYP)/6-311++G(3df,3pd) potential energy surface of the molecule, all of them differing in the conformation of the allyl substituent. According to the calculations, in the gaseous phase all conformers are significantly populated (TSk:TC:GSk: $G S k^{\prime}: G C=47 \%: 16 \%: 18 \%: 12 \%: 7 \%$, at $\left.350 \mathrm{~K}\right)$. In the cryogenic matrices, however, only the TSk and TC conformers exist due to isomerization from the higher energy gauche forms to the most stable trans isomers during deposition of the matrix (conformational cooling). The observed conformational cooling is in consonance with the low calculated energy barriers for the $G S k \rightarrow T S k, G S k^{\prime} \rightarrow T S k$ and $G C \rightarrow T C$ isomerization processes. Results from annealing experiments in krypton matrix doubtlessly show that in this matrix the order of stability of the TSk and TC conformers is reversed, with the more planar TC form becoming the most stable conformer.
\end{abstract}

\section{Introduction}

Benzisothiazoles are often vital structural units of biologically active systems. In particular, their use as herbicides and antibiotic agents has been extensively described. ${ }^{1-3}$ Benzisothiazoles have also been described as phospholipase inhibitors efficient in the treatment of hepatic diseases. ${ }^{4}$

From a strictly chemical point of view, substituted 1,2benzisothiazole 1,1-dioxides (pseudosaccharins) are recognized as important electron-withdrawing derivatizing agents. ${ }^{5}$ Due to the high electronegativity of the pseudosaccharyl group, ${ }^{6}$ pseudosaccharin $O$-ethers provide efficient nucleofuges in catalyzed reactions, such as heterogeneous transfer hydrogenolysis $^{6-9}$ or cross-coupling with organometalic reagents. ${ }^{6,10,11}$ The strong electron withdrawing effect of the pseudosaccharyl group results in a significant lengthening of the $\mathrm{C}_{\mathrm{A}}-\mathrm{O}$ bond at the expense of the $\mathrm{C}_{\mathrm{R}}-\mathrm{O}$ bond $(\mathrm{R}=$ heteroaromatic ring and $\mathrm{A}=$ alkyl or aryl group), which then gains partial double-bond character. These unusual structural features of the $\mathrm{C}_{\mathrm{R}}-\mathrm{O}-\mathrm{C}_{\mathrm{A}}$ fragment are responsible for the characteristic reactivity of these ethers. ${ }^{7,12-14}$

In a previous work, ${ }^{15}$ the molecular structure of the simplest member of the alkyloxy-1,2-benzisothiazole 1,1-dioxide family, that is, 3-(methoxy)-1,2-benzisothiazole 1,1-dioxide (MBID), has been reported based on the combined approach of the matrix-isolation infrared spectroscopy and high-level quantum chemical calculations. That work represents the basis for the

\footnotetext{
* Corresponding authors (e-mail: angoza@qui.uc.pt, rfausto@ci.uc.pt).

$\dagger$ University of Coimbra.

$\doteqdot$ University of Buenos Aires.

$\S$ Jagiellonian University.

"University of Algarve.
}

structural analysis of more complex members of this family of compounds. In particular, in that previous work we were able to overcome the main problem associated with the theoretical treatment of these compounds: the difficulty to adequately estimate the properties of the $>\mathrm{SO}_{2}$ (or $\mathrm{S}=\mathrm{O}$ ) moiety. ${ }^{15-19}$ Indeed, we were able to show that in order to achieve a good prediction of the properties of this molecular fragment an extensive set of polarization functions must be included in the basis set. ${ }^{15}$ The use of the DFT/B3LYP method with the $6-311++\mathrm{G}(3 \mathrm{df}, 3 \mathrm{dp})$ basis set was found to be appropriate to attain reliable results at moderate computational effort when compared to other theoretical approaches suggested before. ${ }^{17-19}$

As a continuation of our previous work, in the present study we use the same methodological approach to investigate 3-(allyloxy)-1,2-benzisothiazole 1,1-dioxide (ABID), a considerably more complex molecule from the structural point of view. This compound bears a conformationally flexible allyloxy substituent, which has three internal rotation axes, and thus represents a substantially greater challenge to structural and spectroscopic investigation than MBID (which presents only one low energy conformer ${ }^{15}$ ). Our interest for ABID also relies on the fact that it has been shown to undergo easy thermal $O$ to $N$ - rearrangement through both [1,3]- and [3,3]-processes, to give the corresponding $N$-allyl pseudosaccharyl derivatives $;{ }^{20}$ the mechanisms of these rearrangements are not yet fully understood, and the knowledge of the structural and spectroscopic details of ABID is then fundamental to tackle this problem.

\section{Materials and Methods}

Infrared Spectroscopy. 3-Allyloxy-1,2-benzisothiazole 1,1dioxide (ABID), which can be regarded as an imidate, is easily 
obtained from reaction of allyl alcohol (prop-2-en-1-ol) with 3-chloro-1,2-benzisothiazole 1,1-dioxide (saccharyl chloride) in the presence of triethylamine. Detailed synthetic procedures for the preparation of allyloxybenzisothiazoles are described elsewhere. ${ }^{21}$ The compound was obtained as light yellow needles from ethanol, mp $135-136{ }^{\circ} \mathrm{C}$. Analysis: found C, 53.73; $\mathrm{H}$, 4.09; N, 6.25\%. Required for $\mathrm{C}_{10} \mathrm{H}_{9} \mathrm{NO}_{3} \mathrm{~S}$ : C, 53.80; H, 4.06; $\mathrm{N}, 6.27 \% .{ }^{1} \mathrm{H}$ NMR $\left(\mathrm{CDCl}_{3}\right): \delta 5.05(2 \mathrm{H}, \mathrm{d}) ; 5.40-5.60(2 \mathrm{H}$, dd); 6.10-6.20 (1H, m); 7.70-7.80 (3H, m); $7.90(1 \mathrm{H}, \mathrm{d}) . \mathrm{MS}$ $\left(\mathrm{CI} ; \mathrm{NH}_{3}\right): m / z 224(\mathrm{M}+\mathrm{H})^{+}, m / z 241\left(\mathrm{M}+\mathrm{NH}_{4}\right)^{+}$.

In the matrix isolation experiments, a glass vacuum system and standard manometric procedures were used to deposit the matrix gas (argon, 99.99990\%; krypton 99.995\%; both obtained from Air Liquide). Matrices were prepared by co-deposition, onto the cooled CsI substrate of the cryostat $(10 \mathrm{~K})$, of the matrix gas (Ar or $\mathrm{Kr}$ ), and the compound placed in a specially designed temperature variable minioven assembled inside the cryostat. The temperature of the minioven used to evaporate ABID was $350 \mathrm{~K}$. At this temperature, sublimation of the compound occurs without degradation, as noticed by the absence of any band in the spectrum that could be ascribed to any putative products of decomposition (e.g., $\mathrm{SO}_{2}, \mathrm{OCN}, \mathrm{C}_{6} \mathrm{H}_{5}-\mathrm{CH}_{2} \mathrm{CH}=\mathrm{CH}_{2}$ ). After depositing the compound, annealing experiments were performed up to a temperature of 40 and $57 \mathrm{~K}$, for $\mathrm{Ar}$ and $\mathrm{Kr}$, respectively. All experiments were done on the basis of an APD Cryogenics closed-cycle helium refrigeration system with a DE202A expander. The temperature was measured directly at the sample holder by a silicon diode temperature sensor, connected to a digital controller (Scientific Instruments, model 9650-1) with an accuracy of $0.1 \mathrm{~K}$.

The IR spectra were collected, with $0.5 \mathrm{~cm}^{-1}$ spectral resolution, on a Mattson (Infinity 60AR series) Fourier transform infrared spectrometer, equipped with a deuterated triglycine sulfate (DTGS) detector and $\mathrm{Ge} / \mathrm{KBr}$ beamsplitter. Necessary modifications of the sample compartment of the spectrometer were made in order to accommodate the cryostat head and allow efficient purging of the instrument by a stream of dry air to remove atmospheric water and $\mathrm{CO}_{2}$ vapors.

Computational Methodology. The quantum chemical calculations were performed with Gaussian $03^{22}$ using the DFT(B3LYP) method with the $6-311++\mathrm{G}(3 \mathrm{df}, 3 \mathrm{pd})$ basis set. $^{23-26}$

Conformations were optimized using the Geometry Direct Inversion of the Invariant Subspace (GDIIS) method. ${ }^{27,28}$ Vibrational frequencies were calculated at the same level of theory, and the nature of the stationary points on the potential energy surface (PES) resulting from optimization was determined by inspection of the corresponding calculated Hessian matrix. The optimized structures of all conformers were confirmed to correspond to true minimum energy conformations on the PES. The calculated frequencies were also used to assist the analysis of the experimental spectra and to obtain Gibbs energies for the relevant structures using standard thermodynamics under the rigid-rotor harmonic oscillator (RRHO) approximation. The rotational and translational contributions to the Gibbs energies at the temperature of sublimation of the sample $(350 \mathrm{~K})$ were taken from the classical expressions. Due to the molecular size and low symmetry of the molecule under study, the effects due to both centrifugal distortion and Coriolis forces were assumed to be of low importance. The dominant error in the approximation used to compute Gibbs energies is the well-known less good performance of the harmonic approximation for low-frequency vibrations. In the studied molecule, there are several low vibrational frequencies (below 200 $\mathrm{cm}^{-1}$ ). In such cases, in order to get good absolute values for
Gibbs energies it is more appropriate to calculate the thermal component associated with these modes using a hindered rotator approximation. However, in the present study the important thermodynamical data are the relative Gibbs conformational energies and, since the low-frequency modes in all relevant structures have similar frequencies (see tables with calculated frequencies for the various conformers provided in the Supporting Information), no significant errors are expected to occur in these values due to favorable cancelation of errors. Normal coordinate analyses were undertaken in the internal coordinates space as described by Schachtschneider, ${ }^{29}$ using the program BALGA and the optimized geometries and harmonic force constants resulting from the DFT(B3LYP)/6-311++G(3df,3pd) calculations. Potential energy profiles for internal rotation were calculated performing relaxed scans on the PES along the relevant reaction coordinates, and the transition state structures for conformational interconversion were obtained using the synchronous transit-guided quasi-Newton (STQN) method. ${ }^{30,31}$

\section{Results and Discussion}

Geometries and Energies. 3-(Allyloxy)-1,2-benzisothiazole 1,1-dioxide (Figure 1) has three internal rotational axes $\left(\mathrm{N}_{8}=\right.$ $\mathrm{C}_{9} \mathrm{O}_{15} \mathrm{C}_{17}, \mathrm{C}_{9} \mathrm{O}_{15} \mathrm{C}_{17} \mathrm{C}_{20}$ and $\mathrm{O}_{15} \mathrm{C}_{17} \mathrm{C}_{20}=\mathrm{C}_{22}$ ) that could in principle give rise to different conformers. However, all structures identified as minimum energy conformations were found to have the same arrangement around the $\mathrm{C}_{9}-\mathrm{O}_{15}$ bond, defined by a $\mathrm{N}_{8}=\mathrm{C}_{9} \mathrm{O}_{15} \mathrm{C}_{17}$ dihedral angle of $\mathrm{ca}$. $0^{\circ}$ (cis). In this conformational arrangement the allyloxy substituent is kept as far as possible from the benzisothiazole ring, thus avoiding both charge repulsions and steric hindrance between the allyl hydrogen atoms and $\mathrm{H}_{10}$. The main factor contributing to the occurrence of different conformers in ABID is then the orientation of the allyl group, as defined by the $\mathrm{C}_{9} \mathrm{O}_{15} \mathrm{C}_{17} \mathrm{C}_{20}$ and $\mathrm{O}_{15} \mathrm{C}_{17} \mathrm{C}_{20}=\mathrm{C}_{22}$ dihedral angles.

A full conformational search on the potential energy surfaces of ABID allowed the identification of 5 different conformational isomers: $T S k=T S k^{\prime}, T C, G S k=G^{\prime} S k^{\prime}, G S k^{\prime}=G^{\prime} S k$ and $G C=G^{\prime} C$, with zero-point vibrational energy corrected relative energies of $0.00,1.97,2.00,3.82$ and $6.02 \mathrm{~kJ} \mathrm{~mol}^{-1}$, respectively (see Figure 1 and Table 1). In the abbreviations used to name the conformers, the conformation defined by the $\mathrm{C}_{9} \mathrm{O}_{15} \mathrm{C}_{17} \mathrm{C}_{20}$ dihedral angle relates to the first letter $\left(T=\right.$ trans, $180^{\circ} ; G=$ gauche, $c a .60^{\circ} ; G^{\prime}=$ gauche $e^{\prime}$ ca. $-60^{\circ}$ ), whereas that defined by the $\mathrm{O}_{15} \mathrm{C}_{17} \mathrm{C}_{20}=\mathrm{C}_{22}$ dihedral angle determines the second (or second and third) $\left(C=c i s, 0^{\circ} ; S k=\right.$ skew, ca. $120^{\circ} ; S k^{\prime}=$ skew' ${ }^{\prime} \mathrm{ca} .-120^{\circ}$ ). All conformers but $T C$ belong to the $C_{1}$ point group and are doubly degenerated by symmetry. $T C$ corresponds to a single point on the PES of ABID and has $C_{s}$ symmetry. The calculated structural parameters for all 5 conformers of ABID are provided in Table S1 (Supporting Information).

According to the calculations, the two most stable conformers of ABID are TSk and TC, both exhibiting the trans configuration around the $\mathrm{O}_{15} \mathrm{C}_{17}$ bond. This result is in agreement with the well-known trend of molecules containing the $\mathrm{C}(=\mathrm{X}) \mathrm{OCH}_{2} \mathrm{R}$ ( $\mathrm{X}=\mathrm{N}, \mathrm{O} ; \mathrm{R}=$ carbon chain) fragment to assume preferentially the trans conformation of the $\mathrm{C}-\mathrm{O}-\mathrm{C}-\mathrm{R}$ group, in result of the stabilization due to the hyperconjugation involving the two methylene hydrogen atoms and the $\pi$-electron system of the $\mathrm{X}=\mathrm{C}-\mathrm{O}-\mathrm{C}$ fragment (which altogether form a structure equivalent to an unsaturated five membered ring). ${ }^{32}$ Very interestingly, the energy difference between GSk, the most stable of the three conformers of ABID having the gauche orientation of the $\mathrm{C}-\mathrm{O}-\mathrm{C}-\mathrm{R}$ group (in this case $\mathrm{R}=\mathrm{CH}=\mathrm{CH}_{2}$ ), and the lowest energy conformer (TSk) is predicted by the calculations 
TSk

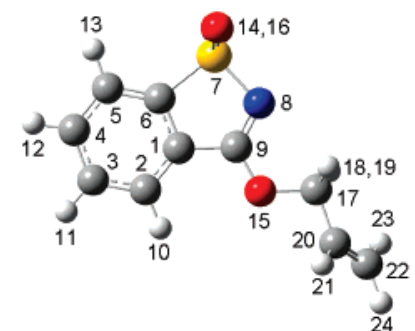

\begin{abstract}
$\begin{array}{ll}\text { Symmetry } \mathrm{C}_{1} & \mathrm{C}_{9} \mathrm{O}_{15} \mathrm{C}_{17} \mathrm{C}_{20}: 177.2^{\circ} \\ \mathrm{E}_{\text {ZPVE }}=-2796218.185 \mathrm{~kJ} \mathrm{~mol}^{-1} & \mathrm{O}_{15} \mathrm{C}_{17} \mathrm{C}_{20} \mathrm{C}_{22}: 124.2^{\circ}\end{array}$ $\Delta \mathrm{E}_{\mathrm{ZPVE}}=0.0$
\end{abstract} $\mu=6.30 \mathrm{D}$

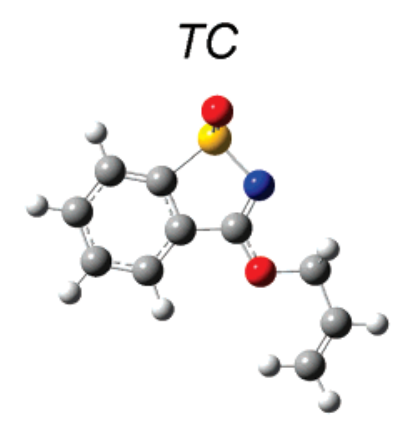
$\begin{array}{ll}\text { Symmetry: } \mathrm{C}_{\mathrm{s}} & \mathrm{C}_{9} \mathrm{O}_{15} \mathrm{C}_{17} \mathrm{C}_{20}: 180.0^{\circ} \\ \Delta \mathrm{E}_{\text {ZPVE }}: 1.97 \mathrm{~kJ} \mathrm{~mol}^{-1} & \mathrm{O}_{15} \mathrm{C}_{17} \mathrm{C}_{20} \mathrm{C}_{22}: 0.0^{\circ}\end{array}$

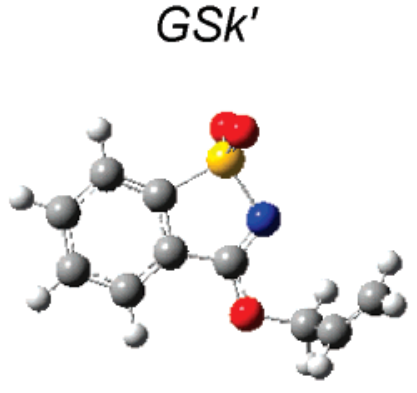

$\begin{array}{ll}\text { Symmetry: } \mathrm{C}_{1} & \mathrm{C}_{9} \mathrm{O}_{15} \mathrm{C}_{17} \mathrm{C}_{20}: 89.9^{\circ} \\ \Delta \mathrm{E}_{\text {ZPVE }}: 3.82 \mathrm{~kJ} \mathrm{~mol}^{-1} & \mathrm{O}_{15} \mathrm{C}_{17} \mathrm{C}_{20} \mathrm{C}_{22}:-120.0^{\circ} \\ \mu=6.12 \mathrm{D} & \end{array}$
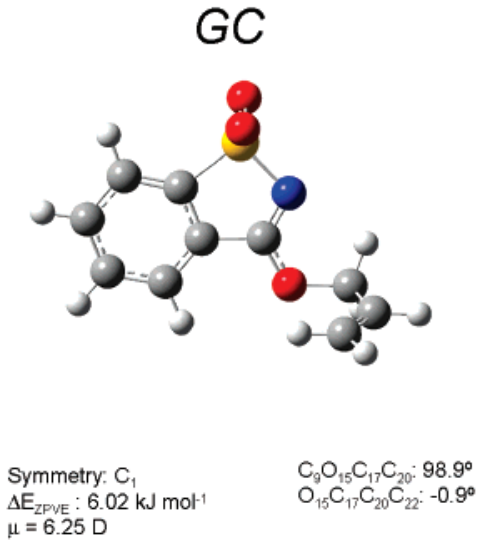

Figure 1. Conformers of ABID with atom numbering scheme. Defining dihedral angles, zero-point vibrational energy corrected relative energies and dipole moments are also shown.

TABLE 1. DFT(B3LYP)/6-311++G(3df,3pd) Calculated Relative Energies, Gibbs Energies and Populations at $350 \mathrm{~K}$ for the Relevant Conformations of $\mathrm{ABID}^{a}$

\begin{tabular}{|c|c|c|c|c|c|c|c|}
\hline molecular species & symmetry & $\Delta E_{\mathrm{ZPVE}}$ & $\Delta E_{\mathrm{ZPVE}}^{\#}$ & $\Delta G_{350}$ & $\Delta G^{\#}{ }_{350}$ & $P_{350}$ & $v_{\mathrm{im}}^{b}$ \\
\hline \multicolumn{8}{|l|}{ conformer } \\
\hline$T S k=T S k^{\prime}$ & $C_{1}$ & 0.00 & & 0.00 & & 47 & \\
\hline$T C$ & $C_{s}$ & 1.97 & & 1.00 & & 16 & \\
\hline$G S k=G^{\prime} S k^{\prime}$ & $C_{1}$ & 2.00 & & 2.79 & & 18 & \\
\hline$G S k^{\prime}=G^{\prime} S k$ & $C_{1}$ & 3.82 & & 4.05 & & 12 & \\
\hline$G C=G^{\prime} C$ & $C_{1}$ & 6.02 & & 5.40 & & 7 & \\
\hline \multicolumn{8}{|l|}{ transition state ${ }^{c}$} \\
\hline$G S k \rightarrow T S k$ & $C_{1}$ & 3.90 & 1.90 & 9.43 & 6.64 & & -36.5 \\
\hline$G S k^{\prime} \rightarrow T S k^{\prime}$ & $C_{1}$ & 5.18 & 1.36 & 10.80 & 6.75 & & -31.9 \\
\hline$G C \rightarrow T C$ & $C_{1}$ & 6.20 & 0.18 & 12.65 & 7.25 & & -23.4 \\
\hline$T S k \rightarrow T S k^{\prime}$ & $C_{s}$ & 6.16 & 6.16 & 9.43 & 9.43 & & -114.9 \\
\hline$T C \rightarrow T S k$ & $C_{1}$ & 9.76 & 7.79 & 12.73 & 11.73 & & -128.5 \\
\hline$G S k^{\prime} \rightarrow G S k$ & $C_{1}$ & 10.90 & 7.08 & 14.21 & 10.16 & & -107.5 \\
\hline$G C \rightarrow G S k$ & $C_{1}$ & 11.17 & 5.15 & 15.35 & 9.95 & & -103.8 \\
\hline$G C \rightarrow G S k^{\prime}$ & $C_{1}$ & 13.50 & 7.48 & 17.31 & 11.91 & & -120.5 \\
\hline$G S k^{\prime} \rightarrow G S k^{d}$ & $C_{1}$ & 29.78 & 25.96 & & & & \\
\hline$G C \rightarrow G^{\prime} C$ & $C_{s}$ & 62.77 & 56.75 & & & & \\
\hline
\end{tabular}

${ }^{a}$ Energies in $\mathrm{kJ} \mathrm{mol}^{-1} . \Delta E_{\mathrm{ZPVE}}=$ zero-point vibrational energy corrected energies relative to the most stable conformation (form $T S k$ ); $\Delta E^{\sharp}{ }_{\mathrm{ZPVE}}$ $=$ zero-point vibrational energy corrected energy barriers of the given transformation; $\Delta G_{350}=$ Gibbs energies at $350 \mathrm{~K}$ relative to the most stable conformer (TSk); $\Delta G_{350}^{\#}=$ Gibbs energies differences between the transition state and the reactant of the indicated transformation; $P_{350}=$ populations $(\%)$ at $350 \mathrm{~K}$, obtained from the calculated Gibbs energies assuming the Boltzmann distribution. Conformer degeneracies were taken into consideration when calculating the populations. ${ }^{b}$ Imaginary frequencies $\left(\nu_{\mathrm{im}}\right)$ in $\mathrm{cm}^{-1}$. For the high-energy transition states associated with the GSk $\rightarrow$ GSk (along the $\mathrm{O}_{15} \mathrm{C}_{17} \mathrm{C}_{20}=\mathrm{C}_{22}$ coordinate) and $G C \rightarrow G^{\prime} C$ isomerizations, no vibrational calculations were performed. ${ }^{c}$ See Figure $\mathrm{S} 1$ for structures of the transition states. ${ }^{d}$ By rotating the $\mathrm{O}_{15} \mathrm{C}_{17} \mathrm{C}_{20}=\mathrm{C}_{22}$ dihedral angle.

to be $2.00 \mathrm{~kJ} \mathrm{~mol}^{-1}$, i.e., practically equal to the energy difference between the gauche and the trans conformers of ethyl formate $\left(2.06 \mathrm{~kJ} \mathrm{~mol}^{-132}\right)$.

Within each one of the two subgroups that can be used to classify the 5 conformers of ABID (I, TSk and TC, with the trans arrangement of the $\mathrm{C}_{9} \mathrm{O}_{15} \mathrm{C}_{17} \mathrm{C}_{20}$ group, and II, GSk, GSk' and $G C$, with the gauche arrangement of this group) the conformers possessing the skew (synclinal) arrangement of the $\mathrm{O}_{15} \mathrm{C}_{17} \mathrm{C}_{20}=\mathrm{C}_{22}$ fragment were found to be more stable than the cis (synperiplanar) forms. Then, in group I the TSk conformer 


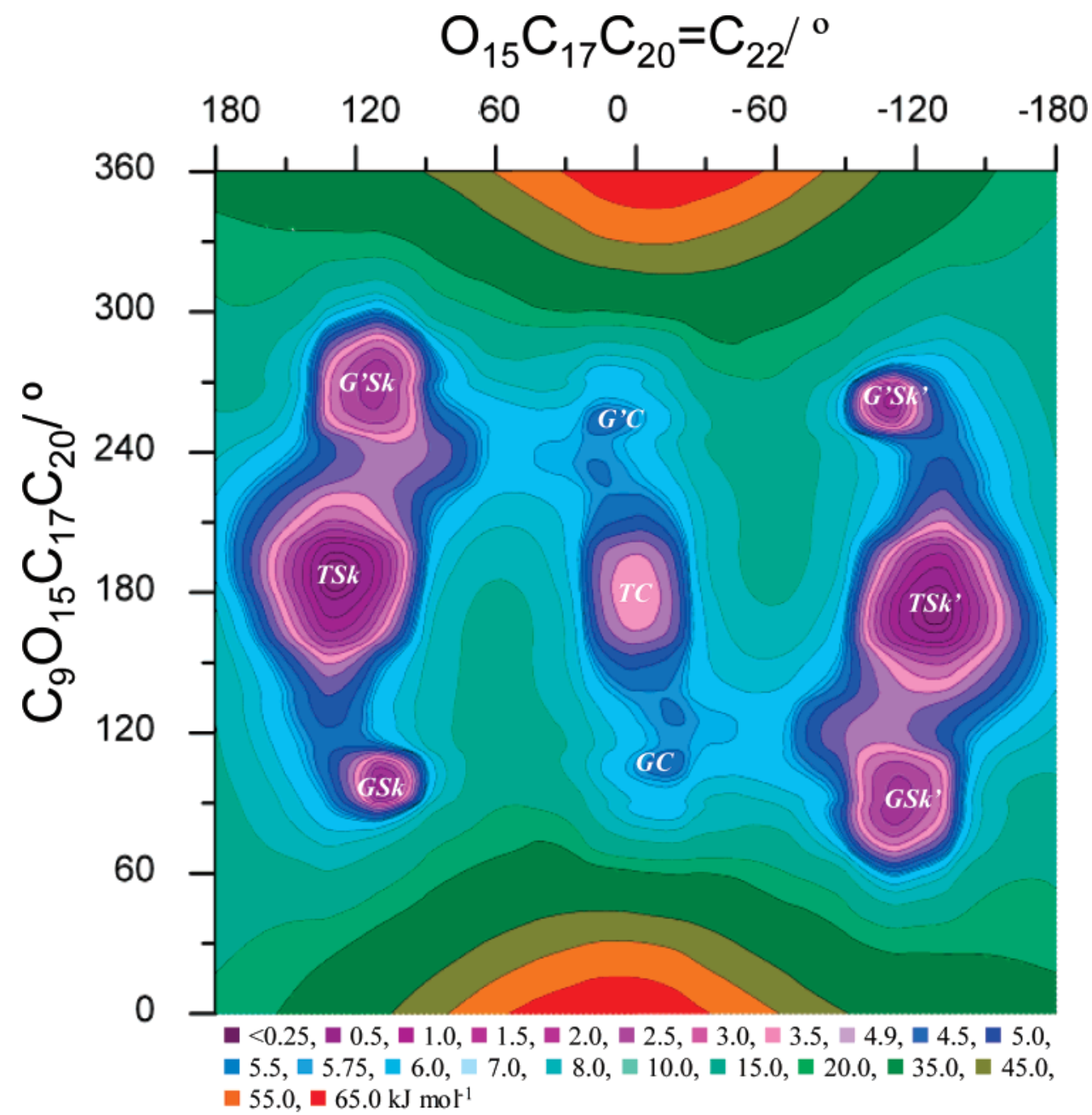

Figure 2. DFT(B3LYP)/6-311++G(3df,3pd) potential energy $\left(\mathrm{kJ} \mathrm{mol}^{-1}\right)$ contour map for $A B I D$ as a function of the $\mathrm{C}_{9} \mathrm{O}_{15} \mathrm{C}_{17} \mathrm{C}_{20}$ and $\mathrm{O}_{15} \mathrm{C}_{17} \mathrm{C}_{20}=$ $\mathrm{C}_{22}$ dihedral angles. Color codes are indicated in the figure. For better insight of the low-energy region, the values corresponding to the $\mathrm{C}_{9} \mathrm{O}_{15} \mathrm{C}_{17} \mathrm{C}_{20}$ dihedral angle are given in the $\left(0,360^{\circ}\right)$ range instead of $\left(-180,180^{\circ}\right)$, so that the $G^{\prime}$ conformation corresponds to values of ca. $270^{\circ}$.

is more stable than $T C$, and in group II the GSk and $G S k^{\prime}$ forms are more stable than $G C$ (see Figure 1). These results follow the general trend exhibited by heteroallyl compounds, as discussed in detail by Kobychev et al. ${ }^{33}$ For 3-hydroxyprop-1ene, 3-methoxyprop-1-ene and formoxime allyl ether, which are molecules exhibiting the $\mathrm{O}-\mathrm{CH}_{2} \mathrm{CH}=\mathrm{CH}_{2}$ moiety common to ABID, the energy differences between the cis and skew conformers were found to range from 0.42 to $3.01 \mathrm{~kJ} \mathrm{~mol}^{-1}, 33,34$ which compare nicely with the energy differences between the cis and skew conformers in ABID: $\Delta E_{T C-T S k}=1.97 \mathrm{~kJ} \mathrm{~mol}^{-1}$; $\Delta E_{G C-G S k}=4.02 \mathrm{~kJ} \mathrm{~mol}^{-1} ; \Delta E_{G C-G S k^{\prime}}=2.20 \mathrm{~kJ} \mathrm{~mol}^{-1}$ (see Figure 1).

Figure 2 shows the potential energy contour map for ABID as a function of the two conformationally relevant dihedral angles: $\mathrm{C}_{9} \mathrm{O}_{15} \mathrm{C}_{17} \mathrm{C}_{20}$ and $\mathrm{O}_{15} \mathrm{C}_{17} \mathrm{C}_{20}=\mathrm{C}_{22}$. The map clearly reveals the positions of the 9 minima in the PES of ABID (corresponding to the 5 different conformers of the molecule) and the pathways for interconversion between them, which imply at a time essentially rotation about one of these angles. The structures and some other relevant data for the transition states associated with these interconversions are provided in Figure S1 (Supporting Information).

Conformational Interconversion by Rotation about the $\mathbf{O}_{15} \mathbf{C}_{17} \mathbf{C}_{20}=\mathbf{C}_{22}$ Dihedral Angle. (i) In the region corresponding to the $\mathrm{C}_{9} \mathrm{O}_{15} \mathrm{C}_{17} \mathrm{C}_{20}$ dihedral angle of $c a .180^{\circ}$ (trans), variation of the $\mathrm{O}_{15} \mathrm{C}_{17} \mathrm{C}_{20}=\mathrm{C}_{22}$ dihedral allows for interconversion between the $T C$ conformer and the two-equivalent-by-symmetry
TSk structures. The potential energy profile corresponding to this interconversion pathway is represented in Figure 3A. As it can be seen in this figure, the energy required to convert the TC conformer into the most stable TSk form is moderately low: $7.79 \mathrm{~kJ} \mathrm{~mol}^{-1}$ (the barrier in the reverse direction is 9.76 $\mathrm{kJ} \mathrm{mol}^{-1}$ ). Interestingly, the barrier for the interconversion between the two TSk equivalent forms does not differ very much from this one: $6.16 \mathrm{~kJ} \mathrm{~mol}^{-1}$. (ii) In the region corresponding to the $\mathrm{C}_{9} \mathrm{O}_{15} \mathrm{C}_{17} \mathrm{C}_{20}$ dihedral angle of $c a .90^{\circ}$, variation of the $\mathrm{O}_{15} \mathrm{C}_{17} \mathrm{C}_{20}=\mathrm{C}_{22}$ dihedral allows for interconversion between the three gauche conformers, GSk, GC and GSk'. The corresponding potential energy profile is depicted in Figure $3 \mathrm{~B}$, resembling closely that presented in Figure 3A. The barriers required to convert the $G C$ form into $G S k$ and $G S k^{\prime}$ are 5.15 and $7.48 \mathrm{~kJ}$ $\mathrm{mol}^{-1}$, respectively (reverse barriers: 9.17 and $9.68 \mathrm{~kJ} \mathrm{~mol}^{-1}$ ). That associated with the $G S k^{\prime} \rightarrow G S k$ process amounts to 7.08 $\mathrm{kJ} \mathrm{mol}^{-1}$ (reverse barrier: $8.90 \mathrm{~kJ} \mathrm{~mol}^{-1}$ ).

Conformational Interconversion by Rotation about the $\mathbf{C}_{9} \mathbf{O}_{15} \mathbf{C}_{17} \mathbf{C}_{20}$ Dihedral Angle. (i) In the region corresponding to the $\mathrm{O}_{15} \mathrm{C}_{17} \mathrm{C}_{20}=\mathrm{C}_{22}$ dihedral angle of $\mathrm{ca}$. $0^{\circ}$, variation of the $\mathrm{C}_{9} \mathrm{O}_{15} \mathrm{C}_{17} \mathrm{C}_{20}$ dihedral leads to interconversion between $T C$ and the two symmetrically equivalent $G C$ structures (Figure 3C). The barrier between these latter is $56.75 \mathrm{~kJ} \mathrm{~mol}^{-1}$, since the associated transition state corresponds to a conformation where the allyl group and the nitrogen atom of the heterocycle are very close to each other and strongly interacting sterically. On the other hand, the calculated barrier for the $G C \rightarrow T C$ 

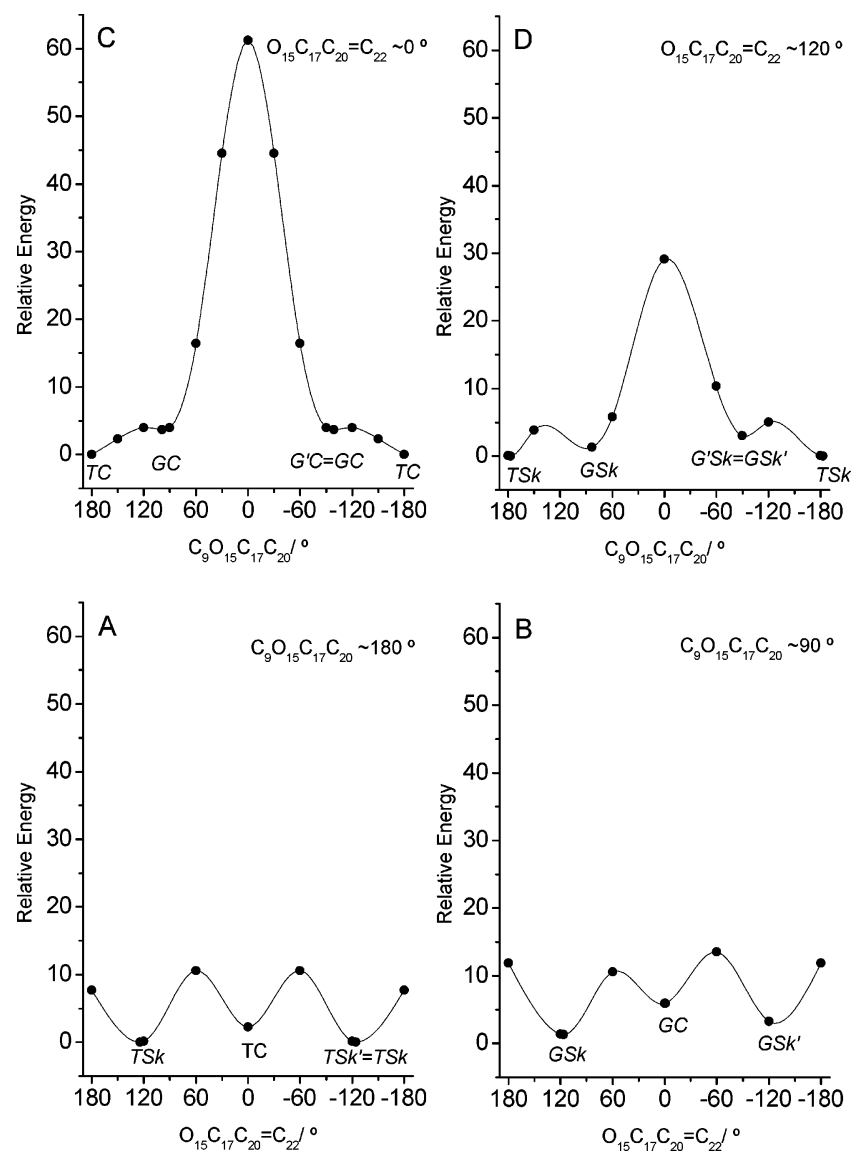

Figure 3. DFT(B3LYP)/6-311++G(3df,3pd) potential energy $(\mathrm{kJ}$ $\mathrm{mol}^{-1}$ ) profiles for the conformational interconversions: (A) TSk $\leftrightarrow$ $T C \leftrightarrow T S k^{\prime}=T S k$; (B) $G S k \leftrightarrow G C \leftrightarrow G S k^{\prime}$; (C) $T C \leftrightarrow G C \leftrightarrow G^{\prime} C=G C$ $\leftrightarrow T C$ and (D) $T S k \leftrightarrow G S k \leftrightarrow G^{\prime} S k=G S k^{\prime} \leftrightarrow T S k$. The ordinate scales of all graphs were chosen equal to emphasize the relative values of the barriers.

conversion is only $0.18 \mathrm{~kJ} \mathrm{~mol}^{-1}\left(6.20 \mathrm{~kJ} \mathrm{~mol}^{-1}\right.$ in the reverse direction). (ii) In the region corresponding to the $\mathrm{O}_{15} \mathrm{C}_{17} \mathrm{C}_{20}=$ $\mathrm{C}_{22}$ dihedral angle of $\mathrm{ca}$. $120^{\circ}$, variation of the $\mathrm{C}_{9} \mathrm{O}_{15} \mathrm{C}_{17} \mathrm{C}_{20}$ dihedral leads to interconversion between TSk, GSk and $G^{\prime} S k=$ $G S k^{\prime}$ structures, i.e., between the 3 skew forms. The potential energy profile associated with this interconversion pathway is shown in Figure 3D (a symmetrically related curve exists for the region corresponding to the $\mathrm{O}_{15} \mathrm{C}_{17} \mathrm{C}_{20}=\mathrm{C}_{22}$ dihedral angle of $c a .-120^{\circ}$, which interconverts $T S k^{\prime}=T S k, G S k^{\prime}$ and $G^{\prime} S k^{\prime}=$ $G S k)$. The obtained profile presents some similarities with that shown in Figure 3C $\left(T C \leftrightarrow G C \leftrightarrow G^{\prime} C=G C \leftrightarrow T C\right)$, in particular a large barrier for conversion between the two gauche structures $\left(G S k^{\prime} \rightarrow G S k: 25.96 \mathrm{~kJ} \mathrm{~mol}^{-1}\right)$ and small barriers between these two forms and TSk $\left(G S k \rightarrow T S k\right.$ and $G S k^{\prime} \rightarrow$ TSk barriers are 1.90 and $1.36 \mathrm{~kJ} \mathrm{~mol}^{-1}$, respectively).

Table 1 shows the calculated relative Gibbs energies for both conformers and relevant transition states at the temperature of the ABID vapor immediately before deposition of the matrices $(350 \mathrm{~K})$. As it can be seen in this table, the relative Gibbs energies of the conformers at $350 \mathrm{~K}$ do not differ significantly from the zero-point vibrational energy corrected conformational energy differences. On the other hand, the $\Delta G^{\#}$ values associated with the transition states for the conformational interconversions

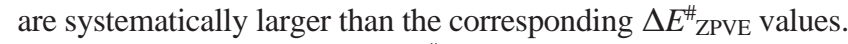
Nevertheless, at $350 \mathrm{~K}$ the $\Delta G^{\#}$ values are still well within the range of values that allow for interconversion between the various conformers to take place easily and, then, all conformers shall exist in an equilibrium in the gas phase at that temperature. From the relative Gibbs energies of the ABID conformers, and taken into account their degeneracy, the relative conformational populations at $350 \mathrm{~K}$ can be estimated as being TSk, TC, GSk, $G S k^{\prime}$ and $G C: 47,16,18,12$ and $7 \%$, respectively. These are then the reference populations of the conformers in the matrix isolation experiments.

The $\Delta E^{\#}$ ZPVE values calculated for the conformational energy barriers are also very important to the interpretation of the matrix isolation experimental data. In fact, these values can be expected to constitute a good approximation to the real energy barriers at the cryogenic temperatures of the matrices. It has been shown that, when these energy barriers are very low (lower than a few $\mathrm{kJ} \mathrm{mol}^{-1}$ ), they can be easily surpassed during deposition of the matrix, because there is still enough thermal energy available in the gaseous beam used to deposit the sample, leading to relaxation of higher energy conformers to lower energy forms. This phenomenon is known as conformational cooling, and has been discussed in deep detail in some of our previous studies. ${ }^{35-39}$ For the present molecule, there are three low-energy barriers which could be expected to be easily overcome during matrix deposition, those corresponding to the GSk $\rightarrow$ TSk $(1.90 \mathrm{~kJ}$ $\left.\mathrm{mol}^{-1}\right), G S k^{\prime} \rightarrow \operatorname{TSk}\left(1.36 \mathrm{~kJ} \mathrm{~mol}^{-1}\right)$ and $G C \rightarrow T C(0.18 \mathrm{~kJ}$ $\left.\mathrm{mol}^{-1}\right)$ isomerizations.

Hence, taking into consideration the calculated values for the barriers to conformational interconversion among the 5 different minima on the PES of the molecule, those corresponding to the three gauche conformers (GC, GSk and $\left.G S k^{\prime}\right)$, though being expected to be experimentally relevant for ABID in the gaseous phase, can be expected to be absent in the low-temperature matrix due to their fast conversion to the most stable trans isomers (TSk and TC) during deposition of the matrix. We can then expect to observe experimentally only two conformers in matrix isolated ABID: the most stable TSk form, with a population given by the sum of its gas-phase population at the temperature of the deposited ABID vapor $(350 \mathrm{~K})$ with those of the GSk and GSk' forms, i.e., 77\%, and the TC conformer, with a relative population of $23 \%$ (sum of its population in the gas phase at $350 \mathrm{~K}$ with that of the $G C$ form).

IR Spectra of the Matrix Isolated Compound: AsDeposited Matrices. Figure 4 shows the spectra of ABID isolated in argon (A) and krypton (B) matrices at $10 \mathrm{~K}$. The experimental spectra are compared with the simulated spectrum of the compound (C), obtained by summing the calculated spectra for the two conformers that are predicted to be present in the matrices (TSk and TC). In building the simulated spectrum, the calculated spectra of the individual conformers (D and E) were weighted by their expected populations in the matrices (TSk, 77\%; TC, 23\%). As shown in Figure 4, the experimental spectra fit nicely the simulated spectrum, thus supporting the conclusions extracted from the analysis of the theoretically predicted PES of the studied compound regarding both relative energies of the conformers in the gas phase and populations predicted on the basis of Gibbs energies at $350 \mathrm{~K}$, as well as the order of magnitude of the barriers for conformational interconversion at cryogenic temperatures. In particular, these results show that the barriers for conformational interconversion do not change considerably in going from gas phase to the matrices (both argon and krypton) and that the GSk $\rightarrow$ TSk, $G S k^{\prime} \rightarrow T S k^{\prime}=T S k$ and $G C \rightarrow T C$ barriers are in all cases the lowest ones separating the GSk, GSk' and GC conformers, respectively, from other lower energy conformers.

The general assignment of the observed spectra was also facilitated by the good agreement between the calculated and experimental data and is presented in Table 2. Tables S2-S7 (Supporting Information) contain the detailed results of the 

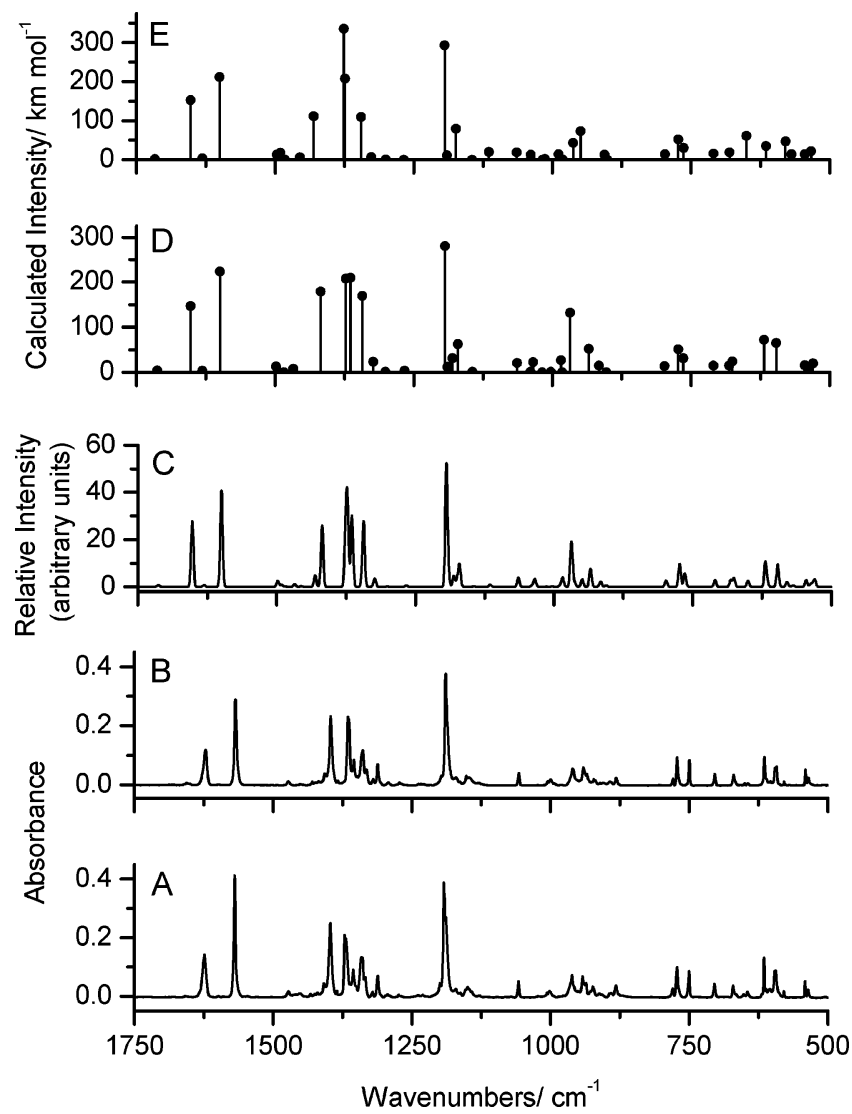

Figure 4. Infrared spectra of ABID in argon (A) and krypton (B) matrices obtained immediately after deposition of the vapor of the compound at $350 \mathrm{~K}$ on the cold substrate of the cryostat kept at $10 \mathrm{~K}$ and DFT(B3LYP)/6-311++G(3df,3pd) calculated spectra: (C) simulated spectrum of the compound obtained by summing the calculated spectra of $T S k$ and $T C$ weighted by their expected populations in the matrices (TSk, 77\%; TC, 23\%; see text); (D) calculated spectrum of $T S k$; (E) calculated spectrum of $T C$.

theoretical calculations of the infrared spectra for the five conformers of ABID and the results of the performed normal coordinate analysis, which support the assignments given in Table 2.

The infrared spectrum of ABID can be considered as being basically constituted by two groups of bands: the first one associated with the vibrations localized in the benzisothiazole ring, and the second related to the allyl vibrational modes. The first group of bands was found to be practically co-incident in all ABID conformers, since the geometry and electronic properties of the bensizothiazole ring unit are nonsignificantly affected by the changes in the conformation of the allyl group (which characterizes the conformers). Hence, only the second group of bands can be used to distinguish spectroscopically the different conformers. In fact, for the two conformers observable in the matrices, which have also the same arrangement around the $\mathrm{N}_{8}=\mathrm{C}_{9} \mathrm{O}_{15} \mathrm{C}_{17}$ dihedral angle (for these two conformers 16 out of the 24 atoms of the molecule then have nearly the same spatial arrangement), the calculations predict that 39 out of the 66 vibrational modes should have frequencies almost coincident, with shifts smaller than $3.5 \mathrm{~cm}^{-1}$ (see Table 2). Since above $1750 \mathrm{~cm}^{-1}$ the experimental intensities are very low (and the signal-to-noise relatively low) and we have no experimental access to the spectral region below $500 \mathrm{~cm}^{-1}$, the number of non-co-incident bands due to the two conformers that could in principle be expected to be observable reduces to only 13 . However, this number does not take into account possible overlaps between bands due to different vibrational modes and the low intensity of some of the "non-co-incident" bands. When these variables are taken into account, the calculations predict that, in the $1750-500 \mathrm{~cm}^{-1}$ spectral range, only the $660-570$ and $1440-1300 \mathrm{~cm}^{-1}$ spectral windows may be useful for clear identification of bands due to the individual conformers (see Table 2). This analysis was, however, facilitated by the examination of the spectral changes resulting from annealing of the krypton matrices, which will be discussed in detail in the next section.

Two additional observations deserve further comments: (a) as expected, the bands originated in the saccharyl moiety of matrix-isolated ABID also appear at nearly the same frequencies as in the analogous saccharin derivarive 3-(methoxy)-1,2benzisothiazole 1,1-dioxide (MBID) ${ }^{15}$ (see Table 2, which also provides the previously reported frequencies for this latter molecule isolated in argon matrix); (b) also as previously observed for $\mathrm{MBID}^{15}$ several bands appear as multiplets not ascribable to different conformers, indicating that the ABID molecules may occupy different matrix sites in both argon and krypton matrices (as discussed in the next section, at least two relevant Fermi resonance interactions - which also lead to band splitting-could also be found in the spectra of matrix-isolated ABID).

IR Spectra of the Matrix Isolated Compound: Annealed Matrices. Since the theoretical calculations predict relatively low-energy barriers for the TC $\rightarrow$ TSk isomerization $(7.79 \mathrm{~kJ}$ $\mathrm{mol}^{-1}$, the barrier in the reverse direction being $\left.9.76 \mathrm{~kJ} \mathrm{~mol}^{-1}\right)$, annealing of the matrices to higher temperatures (up to 40 and $57 \mathrm{~K}$, for argon and krypton matrices, respectively) was carried out in an attempt to change the relative populations of the two conformers and obtain further support to the interpretation of the experimental spectra. In argon, the observed spectral changes were found to be minor and essentially ascribable to siteconversion. However, the experiments carried out in krypton proved to be particularly valuable.

Figure 5 shows $570-660$ and $1300-1440 \mathrm{~cm}^{-1}$ infrared regions of the spectra of ABID in krypton matrix (top spectra) at the deposition temperature (10 K; solid line) and after annealing at $57 \mathrm{~K}$ (dashed line). As discussed above, these two spectral ranges correspond to the two spectral windows that, in agreement with the theoretical calculations, can be useful for identification of bands due to the individual conformers. The spectra presented in the lower panels of this figure are the DFT(B3LYP)/6-311++G(3df,3pd) simulated spectra of the TSk (solid line) and TC (dashed line) conformers. The relative intensities of the bands due to the two conformers in the simulated spectra were weighted by the estimated populations of the two conformers in the as-deposited matrix (TC:TSk $=$ $23 \%: 77 \%$ ). As it can be doubtlessly concluded from this figure, annealing of the krypton matrix led to conversion of the TSk conformer into the $T C$ form (this is particularly clear in the $660-580 \mathrm{~cm}^{-1}$ region, where the correspondence between the experimental and calculated spectra is obvious; the 1440-1300 $\mathrm{cm}^{-1}$ region is more complex and will be discussed in detail below). Observation of the TSk $\rightarrow T C$ isomerization upon matrix annealing was, at the beginning, quite unexpected, since in view of the relative energies of the two conformers predicted theoretically $(T S k<T C)$ the opposite process would be the one that should take place, i.e., conversion from the theoretically predicted less stable TC conformer into the most stable TSk form. Moreover, as shown in the previous section, the relative stability of the two conformers in the gaseous phase is in agreement with the theoretical predictions, the spectra of the as-deposited matrices clearly fitting nicely those predicted on 
TABLE 2: Observed Frequencies for ABID in Argon and Krypton Matrices and Calculated Spectra at the DFT(B3LYP)/ 6-311 $++G(3 d f, 3 p d)$ Level of Theory for the $T S k$ and $T C$ Conformers $^{a}$

\begin{tabular}{|c|c|c|c|c|c|c|c|c|}
\hline \multirow{2}{*}{$\begin{array}{l}\text { Approximate } \\
\text { Description }\end{array}$} & \multicolumn{5}{|c|}{$\underline{\text { Calculated }}$} & \multicolumn{3}{|l|}{ Experimental } \\
\hline & $v_{T S k}$ & $\mathrm{I}_{T S k}$ & $\mathbf{v}_{T C}$ & $\mathrm{I}_{T C}$ & $\Delta v_{(T C-T S k)}$ & Argon & Krypton & MBID (Ar) [13] \\
\hline $\mathrm{v}\left(=\mathrm{CH}_{2}\right)$ as & 3224.5 & 8.0 & 3239.1 & 7.7 & 14.6 & 3104 & & \\
\hline$v(\mathrm{C}-\mathrm{H}$ ring 1$)$ & 3208.9 & 5.8 & 3209.9 & 5.2 & 1.0 & & & \\
\hline$v(\mathrm{C}-\mathrm{H}$ ring 2$)$ & 3205.3 & 2.3 & 3206.0 & 2.8 & 0.7 & 3082 & 3091 & -3076 \\
\hline$v(\mathrm{C}-\mathrm{H}$ ring 3$)$ & 3193.8 & 4.6 & 3194.2 & 4.6 & 0.4 & & & \\
\hline$v(\mathrm{C}-\mathrm{H}$ ring 4$)$ & 3180.7 & 1.2 & 3181.0 & 1.0 & 0.3 & & & \\
\hline$v \mathrm{CH}$ & 3154.0 & 4.9 & & & & 3040 & & \\
\hline $\mathrm{v}\left(=\mathrm{CH}_{2}\right) \mathrm{s}$ & & & $\begin{array}{l}3145.1 \\
3156.9\end{array}$ & $\begin{array}{l}8.1 \\
4.2\end{array}$ & $\begin{array}{l}-8.9 \\
19.8\end{array}$ & $\begin{array}{l}3003 \\
3040\end{array}$ & $\zeta 3010$ & \\
\hline & 3137.1 & 6.4 & & & & -3003 & & \\
\hline $\mathrm{vCH}_{2}$ as & 3107.4 & 3.9 & & & & & & \\
\hline & & & 3069.6 & 5.1 & -37.8 & -2959 & 2965 & \\
\hline$v \mathrm{CH}_{2} \mathrm{~s}$ & 3053.0 & 5.7 & 3036.9 & 6.8 & -16.1 & & & \\
\hline$v \mathrm{C}=\mathrm{C}$ & 1712.8 & 4.5 & 1717.0 & 1.8 & 4.2 & 1658 & 1655 & \\
\hline$v(C-C$ ring 2$)$ & 1652.2 & 146.9 & 1652.3 & 152.8 & 0.1 & 1624 & 1622 & $1635,1633,1629$ \\
\hline$v(\mathrm{C}-\mathrm{C}$ ring 4$)$ & 1631.2 & 3.6 & 1631.0 & 4.0 & -0.2 & 1599 & 1599 & 1599 \\
\hline$v \mathrm{C}=\mathrm{N}$ & 1599.4 & 224.0 & 1600.4 & 212.2 & 1.0 & 1569 & 1568 & 1575,1568 \\
\hline$\delta \mathrm{CH}_{2}$ & 1498.5 & 12.9 & & & & 1472 & 1472 & \\
\hline & & & 1490.7 & 18.1 & -7.8 & 1451 & 1455 & \\
\hline$v(C-C$ ring 6$)$ & 1495.5 & 2.0 & 1497.2 & 13.2 & 1.7 & 1472 & 1472 & 1479 \\
\hline$v(\mathrm{C}-\mathrm{C}$ ring 5$)$ & 1484.0 & 0.3 & 1482.9 & 1.1 & -1.1 & n.obs. & n.obs. & n.obs. \\
\hline$\delta\left(=\mathrm{CH}_{2}\right)$ & 1467.5 & 7.9 & & & & 1431 & 1429,1424 & \\
\hline & & & 1455.6 & 5.8 & -11.9 & 1419 & 1418 & \\
\hline$v \mathrm{C}-\mathrm{O}$ & & & 1430.7 & 111.9 & 12.6 & 1409 & 1408,1403 & $-1383,1378,1376$ \\
\hline & 1418.1 & 179.8 & & & & 1396 & 1396 & \\
\hline $\mathrm{vSO}_{2}$ as & 1372.5 & 208.3 & & & & 1371,1367 & 1365 & $-1370-1322$ \\
\hline $\mathrm{wCH}_{2}$ & 1364.4 & 209.8 & 1374.3 & 208.4 & 1.8 & $\begin{array}{l}1368 \\
1369 \\
1370\end{array}$ & $\begin{array}{l}1364 \\
1367,1365\end{array}$ & \\
\hline$v(C-C$ ring 3$)$ & & & 1345.1 & 109.8 & 2.0 & 1355 & 1354 & $-1315,1313,1312$ \\
\hline & 1343.1 & 169.9 & & & & $1341,1339,1334$ & $1340,1332,1331$ & \\
\hline$\delta \mathrm{CH}$ & 1323.0 & 23.6 & 1326.6 & 7.1 & 3.6 & $1324,1321,1311$ & $1322,1319,1311$ & \\
\hline$\delta(\mathrm{C}-\mathrm{H}$ ring 1$)$ & 1301.0 & 0.6 & 1300.6 & 0.7 & -0.4 & 1297,1294 & 1294,1291 & $1277,1274,1242,1239$ \\
\hline $\mathrm{twCH}_{2}$ & 1266.5 & 3.7 & 1267.9 & 0.5 & 1.4 & 1274 & 1272 & \\
\hline $\mathrm{vSO}_{2} \mathrm{~S}$ & 1193.6 & 280.2 & 1194.6 & 293.9 & 1.0 & - 1199,1192,1188 & $-1197,1189,1185$ & $1199-1190$ \\
\hline$\delta(\mathrm{C}-\mathrm{H}$ ring 3$)$ & 1189.6 & 12.0 & 1190.2 & 11.4 & 0.6 & & & 1187,1185 \\
\hline $\mathrm{w}\left(=\mathrm{CH}_{2}\right)$ & 1180.7 & 31.7 & 1115.0 & 20.1 & -65.7 & $\begin{array}{l}1170 \\
\text { n.obs. }\end{array}$ & $\begin{array}{l}1170 \\
\text { n.obs. }\end{array}$ & \\
\hline$\delta(\mathrm{C}-\mathrm{H}$ ring 4$)$ & & & 1174.3 & 79.8 & 4.0 & 1154,1150 & 1154,1151 & $-1148,1144$ \\
\hline & 1170.3 & 62.8 & & & & 1146,1142 & 1146 & \\
\hline$\delta(\mathrm{C}-\mathrm{H}$ ring 2$)$ & 1144.4 & 1.1 & 1145.3 & 0.5 & 0.9 & 1128 & 1129 & n.obs. \\
\hline$\delta($ ring 1) & 1064.2 & 21.0 & 1064.7 & 18.7 & 0.5 & 1058 & 1057 & 1061,1057 \\
\hline$v(\mathrm{C}-\mathrm{C}$ ring 1$)$ & 1039.5 & 0.6 & 1039.3 & 1.0 & -0.2 & 1006 & 1005 & 1017 \\
\hline$\gamma \mathrm{CH}$ & 1034.6 & 22.4 & 1039.1 & 12.7 & 4.5 & 1102,1000 & 1000 & \\
\hline$\gamma(\mathrm{C}-\mathrm{H}$ ring 2$)$ & 1018.8 & 0.0 & 1017.6 & 0.0 & -1.2 & n.obs. & n.obs. & n.obs. \\
\hline$v C-C$ & 1003.2 & 1.0 & 989.2 & 13.8 & -14.0 & $\left\{\begin{array}{c}\text { n.obs. } \\
961\end{array}\right.$ & $\begin{array}{c}\text { n.obs. } \\
961\end{array}$ & \\
\hline$\gamma\left(=\mathrm{CH}_{2}\right)$ & 984.5 & 26.7 & 963.0 & 43.2 & -21.5 & 941,936 & 941,934 & \\
\hline $\begin{array}{l}\gamma(\mathrm{C}-\mathrm{H} \text { ring } 1) \\
\mathrm{vO}-\mathrm{C}\end{array}$ & $\begin{array}{l}982.5 \\
968.7\end{array}$ & $\begin{array}{r}0.3 \\
132.5\end{array}$ & 981.8 & 0.8 & -0.7 & $\begin{array}{l}\text { n.obs. } \\
941,939,934\end{array}$ & $\begin{array}{l}\text { n.obs. } \\
941,934\end{array}$ & n.obs. \\
\hline & & & 949.3 & 72.9 & -19.4 & 927,923 & 922,919 & \\
\hline$\gamma \mathrm{CH}_{2}$ & 934.4 & 52.5 & & & & 912,908 & 909,893 & \\
\hline$v \mathrm{~N}-\mathrm{S}$ & 916.1 & 15.2 & 1013.6 & 2.0 & 79.2 & $\begin{array}{c}\text { n.obs. } \\
882\end{array}$ & $\begin{array}{c}\text { n.obs. } \\
881\end{array}$ & \\
\hline & & & 906.2 & 13.1 & -9.9 & 871 & 874 & \\
\hline
\end{tabular}


TABLE 2: Continued

\begin{tabular}{|c|c|c|c|c|c|c|c|c|}
\hline \multirow{2}{*}{$\begin{array}{l}\text { Approximate } \\
\text { Description }\end{array}$} & \multicolumn{5}{|c|}{ Calculated } & \multicolumn{3}{|c|}{ Experimental } \\
\hline & $\mathbf{v}_{T S k}$ & $\mathrm{I}_{T S k}$ & $\mathbf{v}_{T C}$ & $\mathbf{I}_{T C}$ & $\Delta \mathrm{v}_{(T C-T S k)}$ & Argon & Krypton & MBID (Ar) [13] \\
\hline$\gamma(\mathrm{C}-\mathrm{H}$ ring 4$)$ & 902.9 & 0.0 & 901.5 & 0.0 & -1.4 & n.obs. & n.obs. & n.obs. \\
\hline$\gamma(\mathrm{C}-\mathrm{H}$ ring 3$)$ & 798.1 & 13.7 & 797.5 & 14.3 & -0.6 & 779 & 779 & $780,779,771,770$ \\
\hline$v \mathrm{C}_{1}-\mathrm{C}_{9}$ & 773.5 & 51.4 & 773.8 & 52.5 & 0.3 & 772,771 & 771 & 768,765 \\
\hline$\gamma(\mathrm{I}-\mathrm{ring})$ & 764.6 & 31.2 & 763.5 & 29.7 & -1.1 & 752,750 & 749 & $756,753,751,750$ \\
\hline$\delta$ (ring 3) & 709.7 & 15.1 & 710.2 & 16.3 & 0.5 & 704 & 704 & 704 \\
\hline$\tau(\mathrm{C}-\mathrm{C}$ ring 1$)$ & 681.7 & 15.2 & 680.6 & 18.6 & -1.1 & & & 673,671 \\
\hline$\tau \mathrm{C}=\mathrm{C}$ & 675.7 & 24.8 & & & & & & \\
\hline$\delta($ ring 2$)$ & 618.9 & 72.5 & 569.2 & 13.7 & -106.5 & $\begin{array}{l}573 \\
615\end{array}$ & $\begin{array}{c}\text { n.obs. } \\
614\end{array}$ & 621 \\
\hline \multirow[t]{2}{*}{$\delta$ (I-ring 1) } & 596.9 & 65.1 & 615.5 & 34.7 & -3.4 & $\begin{array}{l}610 \\
605\end{array}$ & $\begin{array}{l}610 \\
596,592\end{array}$ & $600,597,596,592$ \\
\hline & & & 579.9 & 47.2 & -17.0 & 579 & 579 & \\
\hline$\gamma \mathrm{SO}_{2}$ & 545.4 & 15.3 & 545.1 & 14.3 & -0.3 & 541 & 540 & 542 \\
\hline $\mathrm{wSO}_{2}$ & 537.4 & 7.3 & 534.1 & 22.5 & -3.3 & 536 & 534 & 535 \\
\hline \multirow[t]{2}{*}{$\delta$ (I-ring 2) } & 530.1 & 20.4 & & & & 531 & 530 & \\
\hline & & & 478.0 & 2.3 & -52.1 & n.i. & n.i. & \\
\hline$\tau($ I-ring 2$)$ & 455.1 & 2.1 & 453.5 & 1.5 & -1.6 & n.i. & n.i. & \\
\hline \multirow[t]{2}{*}{$\delta \mathrm{CC}=\mathrm{C}$} & 438.6 & 1.6 & & & & n.i. & n.i & \\
\hline & & & 650.5 & 61.0 & 211.9 & 652,645 & $650,645,643$ & \\
\hline$\tau(\mathrm{C}-\mathrm{C}$ ring 3$)$ & 433.3 & 0.9 & 433.1 & 0.6 & -0.2 & & & \\
\hline$\delta \mathrm{SO}_{2}$ & 393.3 & 5.8 & 391.6 & 4.4 & -1.7 & & & \\
\hline$\delta \mathrm{COC}$ & 313.4 & 1.3 & 333.5 & 2.3 & 20.1 & & & \\
\hline $\mathrm{twSO}_{2}$ & 298.2 & 0.1 & 298.0 & 0.1 & -0.2 & & & \\
\hline$\delta \mathrm{OCC}$ & 280.3 & 3.6 & 204.8 & 1.3 & -75.5 & & & \\
\hline$v \mathrm{~S}-\mathrm{C}$ & 214.9 & 3.1 & 222.3 & 2.7 & 7.4 & & & \\
\hline$\tau \mathrm{C}-\mathrm{O}$ & 203.3 & 1.3 & 212.9 & 3.2 & 9.6 & n.i. & n.i. & \\
\hline Butterfly & 132.3 & 0.2 & 130.8 & 0.3 & -1.5 & 1 & 1 & \\
\hline$\tau \mathrm{C}-\mathrm{C}$ & 119.1 & 0.1 & 155.8 & 0.3 & 36.7 & & & \\
\hline$\tau(\mathrm{C}-\mathrm{C}$ ring 2$)$ & 107.3 & 0.3 & 105.8 & 0.3 & -1.5 & & & \\
\hline$\delta \mathrm{OC}=\mathrm{N}$ & 99.1 & 2.4 & 86.2 & 2.1 & -12.9 & & & \\
\hline$\tau($ I-ring 1$)$ & 60.6 & 1.7 & 72.3 & 1.5 & 11.7 & & & \\
\hline$\tau \mathrm{O}-\mathrm{C}$ & 34.9 & 0.0 & 20.1 & 0.7 & -14.8 & & & \\
\hline
\end{tabular}

${ }^{a}$ Previously reported ${ }^{15}$ bands for 3-(methoxy)-1,2-benzisothiazole 1,1-dioxide (MBID) isolated in argon matrix are also reported for comparison. Wavenumbers in $\mathrm{cm}^{-1}$; calculated intensities in $\mathrm{km} \mathrm{mol}^{-1} ; \nu$, bond stretching; $\delta$, bending; $\gamma$, rocking; w, wagging; tw, twisting; $\tau$, torsion; $\mathrm{s}$, symmetric; as, asymmetric; n.obs., not observed; n.i., not investigated. "ring" and "I-ring" abbreviations refer to benzene and isothiazole rings, respectively. See Table S2 for definition of coordinates. Frequencies shown in bold correspond to bands specifically discussed in the text.

the basis of the calculated populations at the temperature of the deposited vapor of the compound (corrected by the GSk $\rightarrow$ $T S k, G S k^{\prime} \rightarrow T S k$ and $G C \rightarrow T C$ conformational conversions that take place during deposition, as discussed before). Hence, the results of the annealing experiments reveal that the relative stability of the TSk and TC conformers is different in the gaseous phase (where TSk corresponds to the conformational ground state) and in the krypton matrix (where $T C$ is the most stable form).

The relative stabilization of the $T C$ conformer in the matrix can be attributed to the fact that it is more planar than the TSk form, thus perturbing in a less extent the packing requirements of the crystalline solid krypton matrix. Stabilization of more planar conformers in cryogenic rare-gas matrices has been observed previously for other molecules, such as methyl cyanoacetate, ${ }^{40}$ DNA bases ${ }^{41}$ and 1,3-butadiene, ${ }^{42}$ for example. (Very unfortunately, the relative order of stability of the $T C$ and TSk conformers in the argon matrix cannot be determined since, as mentioned, annealing of the argon matrix to the maximum possible work temperature does not promote any conformational isomerization (either $T C \rightarrow T S k$ or $T S k \rightarrow T C$ ). It seems plausible that the more planar $T C$ form is also stabilized in this matrix. However, it is impossible to say to what extent such stabilization occurs and then conclude on the relative stability of the two conformers in this media.)

By comparing the integrated intensities of the bands at 579 $\mathrm{cm}^{-1}[\delta($ I-ring 1$)]$ and $650 / 645 / 643 \mathrm{~cm}^{-1}(\delta \mathrm{CC}=\mathrm{C})$, which belong exclusively to the $T C$ conformer (see Figure 5), in the spectra of the as-deposited matrix and after annealing, it could be found that the TC:TSk population ratio changed from $23 \%$ : $77 \%$ in the as-deposited matrix to $58 \%: 42 \%$ in the annealed matrix at $57 \mathrm{~K}$. If these latter populations correspond to true equilibrium populations at $57 \mathrm{~K}$, then the $T C$ conformer in krypton matrix is more stable than the TSk form by $0.47 \mathrm{~kJ}$ $\mathrm{mol}^{-1}$ (i.e., $T C$ is stabilized by $c a .2 .44 \mathrm{~kJ} \mathrm{~mol}^{-1}$ relatively to TSk upon passing from the gas phase to the krypton matrix). Figure 6 shows the difference spectrum [annealed matrix at 57 $\mathrm{K}$ minus (as-deposited matrix; $10 \mathrm{~K}$ )] of ABID in krypton matrix (top spectrum) and compares it with the simulated theoretical difference spectrum obtained by subtracting the theoretical spectrum of the conformational mixture present in the asdeposited matrix (TC:TSk $=23 \%: 77 \%)$ from the theoretical spectrum of conformational mixture after annealing (TC:TSk $=58 \%: 42 \%$ ). As it can be seen in this figure, the theoretical simulations reproduce very well the experimental data, strongly supporting the presented interpretation. Besides, these results 

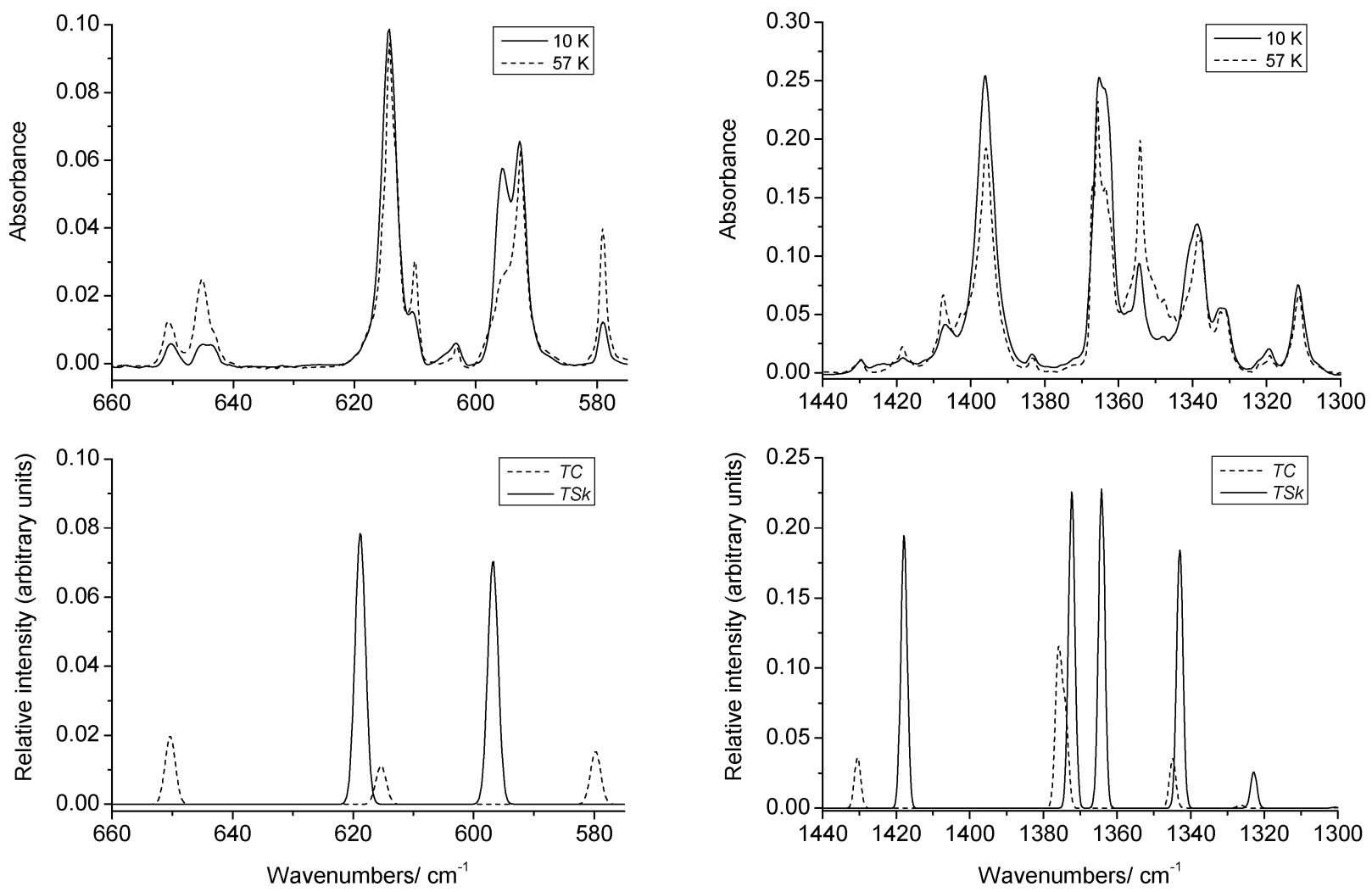

Figure 5. $660-570 \mathrm{~cm}^{-1}$ and $1440-1300 \mathrm{~cm}^{-1}$ infrared regions of the spectra of ABID in krypton matrix (top spectra) at the deposition temperature $(10 \mathrm{~K}$; solid line) and after annealing at $57 \mathrm{~K}$ (dashed line) and DFT(B3LYP)/6-311++G(3df,3pd) simulated spectra of the TSk (solid line) and TC (dashed line) conformers. The relative intensities of the bands due to the two conformers in the simulated spectra were weighted by the estimated populations of the two conformers in the as-deposited matrix (TC:TSk $=23 \%: 77 \%$; see text). The observed splitting of bands $\{$ triplet at 650/645/ $643 \mathrm{~cm}^{-1}(\delta \mathrm{CC}=\mathrm{C} ; T C)$ and doublet at $596 / 592 \mathrm{~cm}^{-1}(\delta(\mathrm{I}$-ring1);TSk)\} result from matrix-site effects. As usually, different sites show different stabilities.
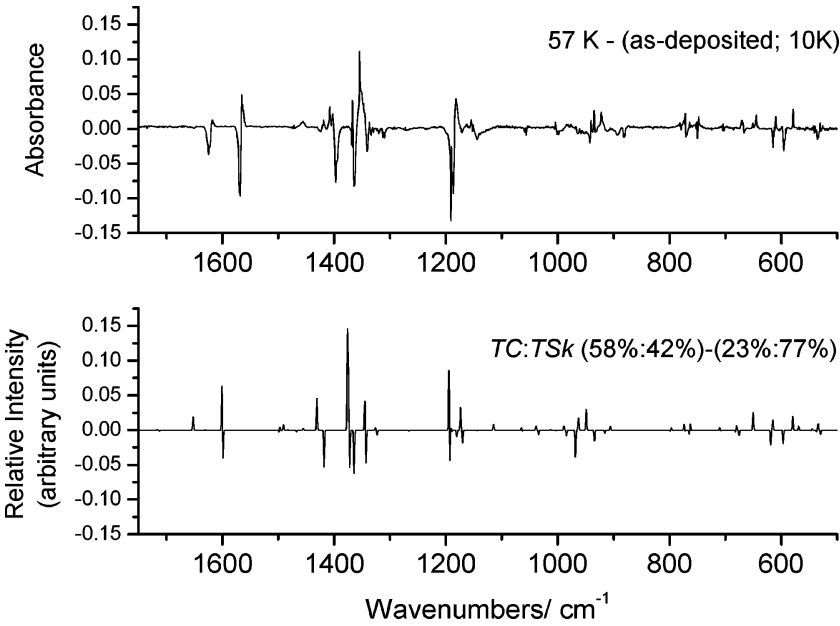

Figure 6. Difference spectrum (annealed matrix at $57 \mathrm{~K}$ minus asdeposited matrix; $10 \mathrm{~K}$ ) of ABID in krypton matrix (top spectrum) and simulated difference spectrum obtained from the DFT(B3LYP)/ $6-311++\mathrm{G}(3 \mathrm{df}, 3 \mathrm{pd})$ calculated spectra of the TSk and TC conformers. The simulated difference spectrum was obtained by subtracting the simulated spectrum of the composition of the conformational mixture present in the as-deposited matrix (TC:TSk $=23 \%: 77 \%$; see text) from the simulated spectrum of the composition of the conformational mixture after annealing (TC:TSk $=58 \%: 42 \%$; see text). In both experimental and simulated difference spectra the bands pointing upward belong to $T C$ and those pointing down to TSk.

also provide an important piece of data for the detailed assignment of the experimental spectrum and identification of bands due to each conformer.
A final comment must be done in relation with the interpretation of the $1440-1300 \mathrm{~cm}^{-1}$ spectral range (see Figure 5). This spectral region, though quite informative, is considerably complex, and it is not so exactly matched by the calculations as other spectral regions (for example, the $660-570 \mathrm{~cm}^{-1}$ region, also shown in Figure 5). The proposed assignments for this spectral region received strong support from the spectral changes observed in the annealing studies. The experimental bands at $1429 / 1424$ and $1418 \mathrm{~cm}^{-1}$ are due to the $\delta\left(=\mathrm{CH}_{2}\right)$ vibrations of TSk and TC, respectively. These bands are predicted at 1467.5 and $1455.6 \mathrm{~cm}^{-1}$ and are not shown in the theoretical spectrum presented in Figure 5, but its assignment is straightforward. The pair of bands at $1408 / 1403 \mathrm{~cm}^{-1}$, which increase in intensity upon annealing of the matrix, are ascribable to the $\nu \mathrm{C}-\mathrm{O}$ vibration of $T C$ in two different matrix sites, while the strong band at $1396 \mathrm{~cm}^{-1}$ is the corresponding vibration in the TSk conformer. For these vibrations, the correspondence with the theoretically predicted bands at 1430.7 and $1418.1 \mathrm{~cm}^{-1}$ is obvious. Less obvious is the assignment of the sets of bands in the $1340-1330$ and $1320-1310 \mathrm{~cm}^{-1}$ regions to essentially the $v(\mathrm{C}-\mathrm{C}$ ring 3$)$ and $\delta \mathrm{CH}$ modes of the TSk conformer (calculated at 1343.1 and $1323.0 \mathrm{~cm}^{-1}$, respectively). However, their approximate "doublet-like" structure can be explained as resulting from Fermi resonance interactions between these fundamental vibrations and the first overtone of the $\tau(\mathrm{C}-\mathrm{C}$ ring 1) mode (fundamental at $670 \mathrm{~cm}^{-1}$ ) and the $\delta$ (ring 3$)+\delta$ (ring 2) combination tone $\left(704+614=1318 \mathrm{~cm}^{-1}\right)$, respectively. The band at $1354 \mathrm{~cm}^{-1}$ and the doublet at $1367 / 1365 \mathrm{~cm}^{-1}$, which are prominent in the spectrum of the annealed matrix, are assigned to the $v(\mathrm{C}-\mathrm{C}$ ring 3$)$ and $\mathrm{wCH}_{2}$ modes of the $T C$ 
conformer, whose calculated values are 1345.1 and $1376.1 \mathrm{~cm}^{-1}$. The $v \mathrm{SO}_{2}$ asymmetric stretching vibration is predicted to occur at similar frequency in both conformers (1372.5 and 1374.3 $\mathrm{cm}^{-1}$ in $T S k$ and $T C$, respectively) and nearly co-incident with the $\mathrm{wCH}_{2}$ mode of $T C$. Hence, these modes shall also contribute to the total intensity of the band at $1365 \mathrm{~cm}^{-1}$, while the $\mathrm{wCH}_{2}$ mode of the TSk form (predicted at $1364.4 \mathrm{~cm}^{-1}$ ) is assigned to the experimentally observed feature at $1364 \mathrm{~cm}^{-1}$. What is important to stress here for a clear and fast interpretation of the data shown in Figure 5 is that all modes predicted to occur within the $1380-1360 \mathrm{~cm}^{-1}$ spectral range give rise to the strong and structured feature appearing within the same frequency interval in the experimental spectrum, while the bands due to the $v(\mathrm{C}-\mathrm{C}$ ring 3$)$ mode in the two conformers, though doubtlessly assigned, were predicted considerably closer to each other in frequency than observed experimentally.

\section{Conclusions}

The conformational space of the pseudosaccharyl ether 3-(allyloxy)-1,2-benzisothiazole 1,1-dioxide (ABID) in the gaseous phase and for the compound isolated in cryogenic rare gas matrices has been studied by means of infrared spectroscopy and density functional theory (DFT) calculations. Five different low-energy conformers (TSk, TC, GSk, GSk' and GC, with relative energies of $0.00,1.97,2.00,3.82$ and $6.02 \mathrm{~kJ} \mathrm{~mol}^{-1}$, respectively) were found on the DFT(B3LYP)/6-311++G(3df,$3 \mathrm{pd})$ potential energy surface of the molecule. Accordingly to the calculations, in the gaseous phase all conformers are significantly populated (TSk:TC:GSk:GSk'GC = 47\%:16\%: $18 \%: 12 \%: 7 \%$, at $350 \mathrm{~K})$. In the cryogenic matrices, however, only the TSk and TC conformers exist. In the as-deposited matrices, the populations of these two conformers were found to be equal to the sum of their gas-phase populations at the temperature of the deposited ABID vapor $(350 \mathrm{~K})$ with those of the $G S k+G S k^{\prime}$ forms and the $G C$ form, respectively (i.e., TSk:TC $=77 \%: 23 \%$ ), due to isomerization from the higher energy gauche forms to the most stable trans isomers during deposition of the matrix (conformational cooling). The observed conformational cooling is in consonance with the low calculated energy barriers for the $G S k \rightarrow T S k, G S k^{\prime} \rightarrow T S k$ and $G C \rightarrow T C$ isomerization processes.

Annealing of the krypton matrix lead to increasing the population of the $T C$ form, doubtlessly showing that in this matrix the order of stability of the TSk and TC conformers is different than in the gaseous phase: in the gas phase, TSk corresponds to the conformational ground state, while in the krypton matrix the more planar $T C$ isomer becomes the most stable form. These results confirm the trend for stabilization of more planar molecules in cryogenic rare gas matrices that has been already pointed out before for other molecular systems. ${ }^{40-42}$

The infrared spectra of the two conformers experimentally observed in the matrices (both argon and krypton) were analyzed in detail and assigned based on the comparison with the calculated spectra and with the experimental spectra of the analogue compound, 3-(methoxy)-1,2-benzisothiazole 1,1dioxide (MBID), as well as by taking into account the results of the performed annealing experiments.

Acknowledgment. Calculations were partially done at the Academic Computer Center "Cyfronet", Krakow, Poland (Grant KBN/SGI_ORIGIN_2000/UJ/044/1999), which is acknowledged for computing time. The research was supported by the Portuguese Fundação para a Ciência e a Tecnologia (Grant FCT \#SFRH/BPD/17081/2004 and Projects POCI/QUI/59019/2004 and POCI/QUI/58937/2004). A.G.-Z. is member of the Research Career at the National Research Council (Conicet), Argentina.

Supporting Information Available: Tables S1-S7 and Figure S1 as discussed in the text. This material is available free of charge via the Internet at http://pubs.acs.org.

\section{References and Notes}

(1) Otten, M.; von Deyn, W.; Engel, S.; Hill, R.; Kardorff, U.; Vossen, M.; Plath, P. Isoxazole-4-yl-benzoyl derivatives and their use as herbicides. Patent number WO9719076. Internationale Anmeldung veröffentlicht durch die Weltorganisation für geistiges Eigentum.

(2) Wepplo, P. J.; Rampulla, R. A.; Heffernan, G. D.; Cossette, M. V.; Langevine, Ch. M.; Kameswaran, V.; Diehl, R. E.; Fiordeliso, J. J.; Haley, G. J.; Guaciaro, M. A. (2004) Herbicidal 3-heterocyclic substituted benzisothiazole and benzisoxazole compounds. United States Wyeth (Madison, NJ) 6706663 http://www.freepatents online.com/6706663.html.

(3) Gravestock, M. B.; Betts, M. J. (2001) Patent Number: WO9910342. Substituted isoxazolines and their use as antibacterial agents. Internationale Anmeldung veröffentlicht durch die Weltorganisation für geistiges Eigentum.

(4) Eacho, P. I.; Foxworthy-Mason, P. S.; Lin, H. S.; Lopez, J. E.; Mosior, M.; Richett, M. E. (2004) Benzisothiazol-3-one-carboxylic acid amides as phospholipase inhibitors. Patent number: WO2004094394. Internationale Anmeldung veröffentlicht durch die Weltorganisation für geistiges Eigentum.

(5) Brigas, A. F.; Fonseca, C. S. C.; Johnstone, R. A. W. J. Chem. Res. 2002, 6, 299

(6) Alves, J. A. C.; Barkley, J. V.; Brigas, A. F.; Johnstone, R. A. W J. Chem. Soc., Perkin Trans. 2 1997, 669. 5789 .

(7) Brigas, A. F.; Johnstone, R. A. W. Tetrahedron Lett. 1990, 31,

(8) Araújo, N. C. P.; Brigas, A. F.; Cristiano, M. L. S.; Frija, L. M. T.; Guimarães, E. M. O.; Loureiro, R. M. S. J. Mol. Catal. A: Chem. 2004, $215,113$.

(9) Frija, L. M. T.; Cristiano, M. L. S.; Guimarães, E. M. O.; Martins, N. C.; Loureiro, R. M. S.; Bickley, J. J. Mol. Catal. A: Chem. 2005, 242, 242.

(10) Brigas, A. F.; Johnstone, R. A. W. J. Chem. Soc., Chem. Commun. 1994, 1923.

(11) Hussey, B. J.; Johnstone, R. A. W.; Entwistle, I. D. Tetrahedron 1982, 38, 3775 .

(12) Ahn, K. H.; Baek, H. H.; Lee, S. J.; Cho, C. W. J. Org. Chem. 2000, 65, 7690.

(13) Powers, J. C.; Asgian, J. L.; Ekici, O. D.; James, K. E. Chem. Rev. 2002, 102, 4639.

(14) Zani, F.; Vicini, P. Arch. Pharm. Pharm. Med. Chem. 1998, 331, 219.

(15) Kaczor, A.; Almeida, R.; Gómez-Zavaglia, A.; Cristiano, M. L. S.; Fausto, R. J. Mol. Struct. 2007, doi:10.1016/j.molstruc.2007.06.004

(16) Typke, V.; Dakkouri, M. J. Mol. Struct. 2001, 599, 177.

(17) Zeng, A. H.; Yu, L.; Wang, Y.; Kong, Q. Y.; Xu, Q.; Zhou, M. F. J. Phys. Chem. A 2004, 108, 6656.

(18) Borba, A.; Gómez-Zavaglia, A.; Simões, P. N. N. L.; Fausto, R. Spectrochim. Acta A 2005, 61, 1461.

(19) Borba, A.; Gómez-Zavaglia, A.; Simões, P. N. N. L.; Fausto, R. J. Phys. Chem. A, 2005, 109, 3578.

(20) Cristiano, M. L. S.; Brigas, A. F.; Johnstone, R. A. W.; Loureiro, R. M. S.; Pena, P. C. A. J. Chem. Res. 1999, 12, 704

(21) Araujo, N. C. P.; Barroca, P. M. M.; Bickley, J. F.; Brigas, A. F.; Cristiano, M. L. S.; Johnstone, R. A. W.; Loureiro, R. M. S.; Pena, P. C. A. J. Chem. Soc., Perkin Trans. $2002,1,1213$.

(22) Frisch, M. J.; Trucks, G. W.; Schlegel, H. B.; Scuseria, G. E.; Robb, M. A.; Cheeseman, J. R.; Montgomery, J. A., Jr.; Vreven, T.; Kudin, K. N.; Burant, J. C.; Millam, J. M.; Iyengar, S. S.; Tomasi, J.; Barone, V.; Mennucci, B.; Cossi, M.; Scalmani, G.; Rega, N.; Petersson, G. A.; Nakatsuji, H.; Hada, M.; Ehara, M.; Toyota, K.; Fukuda, R.; Hasegawa, J.; Ishida, M.; Nakajima, T.; Honda, Y.; Kitao, O.; Nakai, H.; Klene, M.; Li, X.; Knox, J. E.; Hratchian, H. P.; Cross, J. B.; Bakken, V.; Adamo, C.; Jaramillo, J.; Gomperts, R.; Stratmann, R. E.; Yazyev, O.; Austin, A. J.; Cammi, R.; Pomelli, C.; Ochterski, J. W.; Ayala, P. Y.; Morokuma, K.; Voth, G. A.; Salvador, P.; Dannenberg, J. J.; Zakrzewski, V. G.; Dapprich, S.; Daniels, A. D.; Strain, M. C.; Farkas, O.; Malick, D. K.; Rabuck, A. D.; Raghavachari, K.; Foresman, J. B.; Ortiz, J. V.; Cui, Q.; Baboul, A. G.; Clifford, S.; Cioslowski, J.; Stefanov, B. B.; Liu, G.; Liashenko, A.; Piskorz, P.; Komaromi, I.; Martin, R. L.; Fox, D. J.; Keith, T.; Al-Laham, M. A.; Peng, C. Y.; Nanayakkara, A.; Challacombe, M.; Gill, P. M. W.; Johnson, B.; Chen, W.; Wong, M. W.; Gonzalez, C.; Pople, J. A. Gaussian 03, revision B.01; Gaussian, Inc.: Wallingford, CT.

(23) Becke, A. D. J. Chem. Phys. 1993, 98, 5648.

(24) Lee, C. T.; Yang, W. T.; Parr, R. G. Phys. Rev. B 1988, 37, 785

(25) Vosko, S. H.; Wilk, L.; Nusair, M. Can. J. Phys. 1980, 58, 1200. 
(26) Becke, A. D. Phys. Rev. A. 1988, 38, 3098.

(27) Császár, P.; Pulay, P. J. Mol. Struct. (THEOCHEM) 1984, 114 31

(28) Farkas, O; Schlegel, H. B. J. Chem. Phys. 1999, 111, 10806.

(29) Schachtschneider, J. H. Technical Report; Shell Development Co.: Emeryville, CA, 1969.

(30) Peng, C.; Schlegel, H. B. Isr. J. Chem. 1993, 33, 449.

(31) Peng, C.; Ayala, P. Y.; Schlegel, H. B.; Frisch, M. J. J. Comput. Chem. 1996, 17, 49

(32) Fausto, R.; Batista de Carvalho, L. A. E.; Teixeira-Dias, J. J. C. J. Comput. Chem. 1992, 13, 799.

(33) Kobychev, V. B.; Larionova, E. Yu.; Klyba, N. S. J. Struct. Chem. 2003, 44, 748 .

(34) Badawi, H.; Lorencak, P.; Hillig, K. W., II; Imachi, M.; Kuczkowski, R. L. J. Mol. Struct. 1987, 162, 247.
(35) Reva, I. D.; Stepanian, S. G.; Adamowicz, L.; Fausto, R. Chem. Phys. Lett. 2003, 374, 631.

(36) Gómez-Zavaglia, A.; Fausto, R. Phys. Chem. Chem. Phys. 2003, 5,52

(37) Kaczor, A.; Reva, I. D.; Proniewicz, L. M.; Fausto, R. J. Phys. Chem. A 2006, 110, 2360.

(38) Reva, I. D.; Lopes Jesus, A. J.; Rosado, M. T.; Fausto, R.; Eusébio,

M. E.; Redinha, J. S. Phys. Chem. Chem. Phys. 2006, 8, 5339.

(39) Borba, A.; Gómez-Zavaglia, A.; Fausto, R. J. Mol. Struct. 2006, 794, 196.

(40) Reva, I. D.; Ilieva, S.; Fausto, R. Phys. Chem. Chem. Phys. 2001 3,4235

(41) Sheina, G. G.; Ivanov, A. Yu. Vestn. Moscow State Univ., Ser. 2 Chem. 1995, 36, 3755. (Russian).

(42) Kofranek, M.; Karpfen, A.; Lischka, H. Chem. Phys. Lett. 1992, 189, 281. 